\title{
"My Cancer Is Worth Only Fifteen Weeks"? A Critical Analysis of the Lived Experiences of Financial Toxicity and Cancer in Canada
}

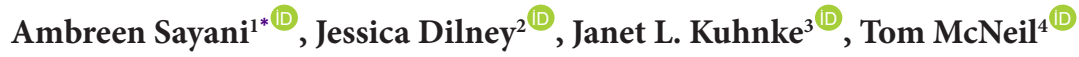

Abstract

Background: Cancer patients experience financial hardship due to rising expenses related to cancer treatment and declining income levels associated with reduced employability. Employment Insurance Sick Benefits (EI-SB) is a social income support program which provides temporary income replacement to Canadians when they fall ill. Although EI-SB is designed to maintain continuity of income during an illness, little is known about the perspectives of cancer patients who receive EI-SB. This knowledge can inform the development of public policies which are responsive to the needs and priorities of cancer patients.

Methods: We conducted a theory-informed thematic analysis of data collected from twenty semi-structured interviews with participants who were receiving care in a cancer centre in Cape Breton, Nova Scotia and had received EI-SB. A coding framework was developed using Taplin and colleagues' intermediate outcomes of patient care across the cancer care continuum. Interpretation of findings was guided by the synergies of oppression theoretical lens.

Results: Three overarching themes describe the experiences of cancer patients receiving social income support: Economic exclusion, in which the structure of the labour market and social welfare system determine access to workplace benefits and continuity of reasonable income; financial toxicity, a vicious cycle of financial burden and increasing financial distress; and constrained choices, where cancer influences employability and lowered income influences the need to be employed.

Conclusion: Cancer patients need income support programs that are tailored to match their healthcare priorities. In addition, policies which strengthen working conditions and facilitate a reintegration to work when possible will be important in addressing the structural drivers of income insecurity experienced by cancer patients.

Keywords: Canada, Cancer, Income Security, Financial Toxicity, Social Benefits, Income Replacement

Copyright: (C) 2022 The Author(s); Published by Kerman University of Medical Sciences. This is an open-access article distributed under the terms of the Creative Commons Attribution License (https://creativecommons.org/licenses/ by/4.0), which permits unrestricted use, distribution, and reproduction in any medium, provided the original work is properly cited.

Citation: Sayani A, Dilney J, Kuhnke JL, McNeil T. “My cancer is worth only fifteen weeks?” A critical analysis of the lived experiences of financial toxicity and cancer in Canada. Int J Health Policy Manag. 2022;11(9):18141822. doi:10.34172/ijhpm.2021.83
\end{abstract}

\section{Article History:}

Received: 15 October 2020 Accepted: 12 July 2021 ePublished: 15 August 2021

\section{Background}

Statistically, 1 in every 2 Canadians can expect to face a diagnosis of cancer over their lifetime. ${ }^{1}$ With a 5 -year survival for all cancers combined at $67 \%,{ }^{2}$ approximately $2.4 \%$ of the Canadian population is currently alive with a diagnosis of cancer. ${ }^{3}$ Survivorship is associated with significant financial adversity as cancer patients frequently find themselves trapped between rising expenses related to cancer-care ${ }^{4-11}$ on one hand and reduced employability with declining levels of personal income ${ }^{12-14}$ on the other hand. Being unemployed or having a low income is associated with poorer cancer adjustment, increased health problems, reduced quality of life, and earlier mortality. ${ }^{4,5,8,15,16}$ For cancer patients, financial stability is an important part of maintaining living conditions, dignity and self-respect. ${ }^{17}$

On average cancer patients report taking 151 days of sick leave following their diagnosis and up to a third are unable to return to work. ${ }^{18}$ The ability to return to work is dependent on the age at diagnosis, site of cancer, intensity of treatment, frequency of physical symptoms, or flexible employment and availability of (re)training services. ${ }^{18,19}$ Return to work is also directly related to significantly high out-of-pocket costs related to medical care and non-medical expenses ${ }^{4-7}$ which can lead to a balancing act where patients may choose to skip medications or prioritise returning to work over receiving treatment. ${ }^{20}$ This financial burden of cancer is amplified at the intersections of marginalizing social identities such that gender, race and access to resources such as housing and employment determine the degree of vulnerability experienced resulting in higher mortality and poorer quality of life for individuals living with social disadvantage. ${ }^{21-24}$

In Canada, a patchwork of income replacement programs are in place to support individuals when they are required to take time off work due to an illness (Table 1). Less than half of all Canadians are supported with workplace benefits which can provide adequate income coverage ${ }^{25}$ and subsequently 


\section{Key Messages}

Implications for policy makers

- One in every two Canadians will face a diagnosis of cancer over the course of their lifetime. For cancer patients who are employed this can cause a disruption to their ability to earn income and subsequently cancer patients will resort to workplace benefits or income replacement programs offered through social welfare to meet their financial needs.

- Individuals employed in precarious working conditions, ie, temporary or contractually based employment with little or no benefits are more likely to report financial hardship and difficulty in returning to work after being diagnosed with cancer.

- Cancer patients who depend on publicly-funded income replacement programs such as Employment Insurance Sick Benefits (EI-SB) and Canada Pension Plan Disability (CPP-DB) find the programs ill-suited to the chronicity of cancer and the complexity of cancer treatment resulting in a perpetual struggle to make ends meet.

- Upstream public policies which strengthen working (and return to work) conditions must be combined with a redesign of both EI-SB and CPPDB to match the needs of cancer patients. This response is needed in order to prevent the economic exclusion of cancer patients, enhance their quality of life and support their recovery.

Implications for the public

In Canada, income replacement programs provide financial compensation to individuals when they need to take time off work due to cancer. These programs are a patchwork of private programs (provided as workplace benefits) and public programs (provided through social services). Individuals working in temporary positions often do not have access to any workplace benefits and must rely upon income replacement programs such as Employment Insurance Sick Benefits (EI-SB) and Canada Pension Plan Disability Benefits (CPP-DB) in order to make ends meet. The duration and amount of income offered through these programs do not match the chronicity of cancer and the complexity of cancer treatment leaving cancer patients in financial hardship. Strong workplace benefits, an ability to return to decent work after cancer, and a revision of the EI-SB and CPP-DB benefits will be necessary in order to provide cancer patients with the support needed to recover from cancer and experience a good quality of life.

most individuals will depend on publicly funded programs such as Employment Insurance Sick Benefits (EI-SB) for financial support when they fall ill. EI-SB provides significantly less income and is means-tested so individuals must prove eligibility by meeting certain criteria. To receive EI-SB, cancer patients must have accumulated more than 600 insured hours over a 52 week employment period and can expect to receive up-to a maximum of $55 \%$ of their regular work earnings for a duration of 15 weeks. ${ }^{26}$ Whilst it is understood that cancer patients experience financial hardship and reduced employability, little is currently known about the perspectives of patients who depend on EI-SB for income support. Understanding these lived experiences can illuminate the needs and priorities of cancer patients and inform the development of cancer-patient responsive public policies.

\section{Methods}

Study Design and Theoretical Approach

Research ethics board approval was obtained from Nova Scotia Health Authority Research Ethics Board. We used theoretical thematic analysis as a way to conceptualise the research questions, collect the study data, and interpret our findings ${ }^{27}$ using the synergies of oppression analytical lens. ${ }^{28}$ The synergies of oppression is a theoretical lens which conceptually locates the intersections of social identity (such as gender, age and disability) with the social determinants of health (such as income and education) and social geography (such as service accessibility and urban or rural location). This theoretical tool has been previously applied to conceptualise the structural inequalities which underpin inequities in breast cancer care, ${ }^{23}$ genetic testing for heredity breast cancer, ${ }^{29}$ access to lung cancer screening ${ }^{30}$ the development of national cancer control policies, ${ }^{31}$ and can inform the interpretation of patient perspectives on EI-SB based on social location. We coded our data using a framework developed from Taplin and colleagues $^{32}$ intermediate outcomes of patient care across the cancer care continuum. These indicators include the stage of cancer diagnosis, quality of life, quality of death and financial burden. ${ }^{32}$

Our study questions were:

1. What is the cancer patients experience of receiving EI$\mathrm{SB}$ ?

2. What is the impact on quality of life for cancer patients who depend on income support programs such as EI-SB?

3. How can cancer patients be better financially supported?

\section{Participant Recruitment and Setting}

Participants were individuals who had been diagnosed with cancer and had received social income support. Participants were recruited to the study through one of the following ways: ( $i$ ) potential participants were informed of the study by a social worker within the patients circle of care and handed a study poster; ( $i$ ) posters were placed in the waiting area of the social services department in the cancer care centre under the Nova Scotia Health Authority; (iii) information about the study was shared through radio and newspaper advertising. Interested participants called a telephone number (directed to TM) that was shared through the posters and media. During this phone call, eligible participants agreed on a date and time for the interview. Participants were included if they were patients of the Cape Breton Cancer Centre and had received EI-SB. Participants were not excluded if they were or had ever received additional income support including Canada Pension Plan Disability Benefits (CPP-DB), short or longterm disability. Participants were informed of the purpose of the interview, approximate duration, and potential harms and benefits of participation. Participants who agreed to take part in the study provided written consent before interviewing began. 
Table 1. Summary of Canadian Income Support Programs

\begin{tabular}{|c|c|c|c|}
\hline Benefit & Who Is Eligible? & What Is Covered? & Notes \\
\hline $\begin{array}{l}\text { El-SB } \\
\text { (Government of } \\
\text { Canada program) }\end{array}$ & $\begin{array}{l}\text { - Paid El premiums. } \\
\text { - Unable to work due to a medical reason. } \\
\text { - Regular weekly earnings must have decreased by more than } \\
40 \% \text {. } \\
\text { - Have accumulated } 600 \text { insured hours in the last } 52 \text { weeks. }\end{array}$ & $55 \%$ of work earnings for 15 weeks. & \\
\hline $\begin{array}{l}\text { CPP-DB } \\
\text { (Government of } \\
\text { Canada program) }\end{array}$ & $\begin{array}{l}\text { - Must have contributed to CPP in } 4 \text { of the last } 6 \text { years; or } 3 \text { of } \\
\text { the last } 6 \text { years if you have contributed for at least } 25 \text { years. } \\
\text { - Medical condition must be considered both severe and } \\
\text { prolonged. Severe refers to being incapable of regularly } \\
\text { pursuing any substantially gainful occupation. Prolonged } \\
\text { refers to the illness being long continued and of indefinite } \\
\text { duration or is likely to result in death. } \\
\text { - Have to be between the ages of } 18 \text { and } 64 \text {. }\end{array}$ & $\begin{array}{l}\text { Pays flat rate of } \$ 485.20 \text { (2018) } \\
\text { plus } 75 \% \text { of a person's calculated } \\
\text { CPP retirement pension. Maximum } \\
\text { monthly benefit (2020) } \$ 1175.83 \text {; } \\
\text { average monthly benefit (2020) } \\
\$ 672.87 \text {. }\end{array}$ & \\
\hline $\begin{array}{l}\text { Short-term } \\
\text { Disability }\end{array}$ & $\begin{array}{l}\text { Income replacement offered through the employer usually } \\
\text { 9-52 weeks; average length } 6 \text { months. }\end{array}$ & $55 \%-70 \%$ of work income. & \\
\hline $\begin{array}{l}\text { Long-term } \\
\text { disability }\end{array}$ & $\begin{array}{l}\text { Income replacement insurance offered through employer 2-3 } \\
\text { years or longer, possibly until age } 65 .\end{array}$ & $60 \%-70 \%$ of work income. & $\begin{array}{l}\text { Deducted dollar for dollar } \\
\text { by Long-term disability if } \\
\text { also approved for CPP-DB. }\end{array}$ \\
\hline $\begin{array}{l}\text { El regular benefits } \\
\text { (Government of } \\
\text { Canada program) }\end{array}$ & $\begin{array}{l}\text { Income replacement for individuals who have lost their jobs } \\
\text { through no fault of their own (but not because of sickness). } \\
\text { Must have been employed in insurable employment; have } \\
\text { been without work and without pay for at least seven } \\
\text { consecutive days in the last } 52 \text { weeks; have worked for the } \\
\text { required number of insurable employment hours in the last } \\
52 \text { weeks or since the start of last El claim, whichever is } \\
\text { shorter. }\end{array}$ & $\begin{array}{l}55 \% \text { of average insurable earnings, } \\
\text { up to a maximum amount weekly } \\
\text { ( } \$ 573 / \mathrm{wk} \text { for 2020). Eligible to } \\
\text { receive from } 14 \text { weeks to a maximum } \\
\text { of } 45 \text { weeks. }\end{array}$ & $\begin{array}{l}\text { People off work due to } \\
\text { illness not eligible. }\end{array}$ \\
\hline
\end{tabular}

Abbreviations: CPP, Canada Pension Plan; EI-SB, Employment Insurance sickness benefits; CPP-DB, Canada Pension Plan Disability Benefits; EI, Employment Insurance.

\section{Data Collection}

Data were collected through semi-structured interviews conducted face-to-face. The interview guide was developed by one social worker of the cancer centre, and reviewed by another social worker. During the interviews, participants were asked about their cancer diagnosis, treatment and side-effects. In addition, participants were asked about their current sources of income and their experiences with EI-SB. All interviews were conducted by 2 social workers who are part of the research team (JD and TM). Interviewing continued until no new themes emerged and conceptual saturation ${ }^{33}$ was reached after interviews with twenty participants. Interviews were audio-recorded with participants permission and transcribed verbatim. ${ }^{34}$ To ensure validity transcripts were reread. Field notes taken during the interviews were added to the transcribed files. All data was entered into a qualitative software program (NVivo version 12) for data management.

\section{Data Analysis}

All authors read through the transcripts individually, and subsequently met to identify initial codes and create an overarching coding framework based on Taplin and colleagues' intermediate indicators of patient outcomes in cancer care. ${ }^{32}$ Subsequently, line-by-line coding was applied to the texts. Additional codes were developed and modified through group peer discussion until all lines of text had been coded. Figure 1 shows the coding tree framework and sample codes. The multidisciplinary nature of the research team enhanced reflexivity ${ }^{35}$ allowing us to code any data which did not match our theoretical inquiry. AS is a medical doctor and critical qualitative researcher on health inequities. JD and TM are social workers in a cancer care centre and clinical researchers. JK is a registered nurse and a healthcare researcher. We identified our final 3 themes through iterative discussions between the research team.

\section{Results}

Characteristics of the Study Sample

We interviewed 20 participants (14 female, and 6 male) who had been diagnosed with cancer and had received EI-SB. Two participants were below the age of 51 years; 16 participants were between 51-64 years of age; and 2 participants were over the age of 65 years. All study participants were ethnically white Caucasian. Seven participants recounted their cancers as early stage (stage 1 or 2), 5 participants reported advanced cancer (stage 3 ) and 8 participants described their cancer as metastatic (stage 4). Participants also recounted receiving a patchwork of income support through Canada Pension Plan (CPP), CPP-DB, Regular Employment Insurance (EI), Income Assistance through welfare, and/ or the Cape Breton Cancer Centre Patient Fund. The Cape Breton Cancer Centre Patient Care Fund is a charity established in 2005 at the Cape Breton Cancer Centre in conjunction with the hospital foundation of the Cape Breton Regional Hospital. It is funded 


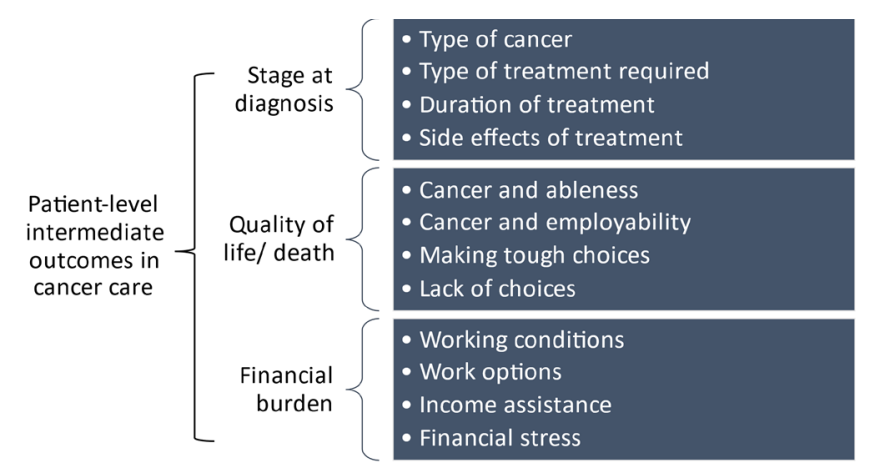

Figure 1. Coding Tree Based on Taplin and Colleagues' Intermediate Indicators of Patient Outcomes in Cancer Care and Sample Codes.

by community donors. It financially aids patients of the Cape Breton Cancer Centre with expenses that have resulted from a cancer diagnosis. These expenses include, but are not limited to, medical travel and lodging, medical equipment, private homecare, prescriptions and household expenses. Participant characteristics are described in Table 2.

\section{Themes}

Figure 2 shows the main themes and subthemes of our study: Economic exclusion, financial toxicity and constrained choices. The findings are discussed in detail below:

\section{Economic Exclusion}

Economic exclusion is described as the systematic and structural economic divide between individuals which occur as a result of labour market policies and social welfare systems that fail to fairly distribute and redistribute economic assets in society. ${ }^{36,37}$

In our study, participants described how their economic stability and access to benefits was determined by their employment status prior to being diagnosed with cancer. Most participants recounted being employed in precarious working conditions with little or no access to any health plans or income support as described by this participant:

"There was no plan through my work. I work for a company that unless you work 30 hours a week you're not going to be on their medical plan, and most places you work for today, you know, you are working the minimum wage job, you know? They are going to keep you under those 30 hours because they don't want you to be on the plan so you're not going to get the benefits" (PP16).

Being employed in a contract job also implied that participants lost their jobs as a result of their cancer diagnosis as recounted by this participant:

"I was in a contract, so I had to walk away from the contract when I got diagnosed" (PP19).

Subsequent to cancer, all participants experienced unemployment. All participants had applied for and received EI-SB. Most participants recounted the income amount received through EI-SB as a bare minimum as recounted below:

"If all we are giving them is bare bones minimum income, and that's really what EI is" (PP19).
Participants described the challenge of meeting their daily needs when income had been halved through EI-SB. This participant recounted the irony of receiving half of their regular income, when needs and expenses could not in turn be halved:

"If you take a person that's making $\$ 500$ a week and then all of a sudden they are forced into this situation (receiving $E I-S B)$ and they're getting half of that (amount), well, you can't go to your local grocery store and they're going to charge you half your grocery bill because of your situation. So, you know, and that pertains to everything you do. They're not going to start cutting things in half for you" (PP10).

Participants described the duration of EI-SB (15 weeks maximum) as a complete mismatch with a chronic illness such as cancer for which treatment was complicated and lengthy:

"Like you know for people who are diagnosed with cancer, if they can figured out a way to help people or cure people with cancer in 15 weeks then I am all for it but there is no way when you are diagnosed with cancer that you can survive on 15 weeks of EI" (PP11).

Participants described the 15 week duration of EI-SB as short and insufficient. For participants with advanced stage cancer this was particularly arduous. One participant with terminal cancer drew parallels between the duration of EISB (15 weeks) and regular EI benefits (1 year) for which they were ineligible:

"It seemed so short at the time (15 weeks), and then all of the sudden, it was finished. I was in the middle of dying from cancer for God sake. You know, if you lose your job, you have a year, but if you have cancer you have 15 weeks. I don't understand that" (PP20).

Participants used words such as, "slapped," "kicked" and "worth" to describe their frustration at not being able to tap into regular EI after having paid into it throughout the period of their employment:

"When you worked all of these years why can't you collect regular EI with it? It does not make sense. There are all of those years that I worked. Why? To get slapped in the face with $\$ 650$ a month" (PP12).

"After paying into the EI for so many years you feel like you are just kicked while you are down" (PP11).

"My cancer is only worth 15 weeks?" (PP2).

After termination of EI-SB, participants described their struggle to prove eligibility for other income support programs. For CPP-DB, participants with early stage cancer were not considered eligible. This participant was denied $\mathrm{CPP}-\mathrm{DB}$ twice as he could not prove that his cancer was severe enough:

"I applied for Canada Pension and I was denied twice. Cancers (are) not considered severe or prolonged. But, cancer can kill you! But, (they say) it's not severe! So that's iffy on my part” (PP1).

\section{Financial Toxicity}

Financial toxicity is described as the objective (financial burden) and subjective (financial distress) experience of economic strain. ${ }^{9}$

Several participants recounted how financially coping with 
Table 2. Participant Characteristics

\begin{tabular}{|c|c|c|c|c|c|c|c|c|c|c|c|c|c|c|c|c|c|}
\hline \multirow[b]{2}{*}{$\begin{array}{l}\text { Participant } \\
\text { ID }\end{array}$} & \multirow[b]{2}{*}{ Age } & \multirow[b]{2}{*}{ Gender } & \multirow[b]{2}{*}{ Ethnicity } & \multirow[b]{2}{*}{$\begin{array}{l}\text { Cancer } \\
\text { Site }\end{array}$} & \multirow[b]{2}{*}{$\begin{array}{l}\text { Cancer } \\
\text { Stage }\end{array}$} & \multirow{2}{*}{$\begin{array}{c}\text { NS-SEC } \\
\text { Occupational Class } \\
\text { Prior to Cancer } \\
\text { Diagnosis }\end{array}$} & \multirow[b]{2}{*}{$\begin{array}{l}\text { Employment } \\
\text { Status at Time } \\
\text { of Interview }\end{array}$} & \multirow[b]{2}{*}{$\begin{array}{c}\text { Workplace } \\
\text { Benefits }\end{array}$} & \multicolumn{8}{|c|}{ Benefits Accessed ( $\mathrm{Y}=$ Yes; $\mathrm{N}=\mathrm{No}$ ) and STATUS (Amount/Month; or Eligibility) } & \multirow[b]{2}{*}{$\begin{array}{l}\text { Time in Weeks } \\
\text { Without Any } \\
\text { Income }\end{array}$} \\
\hline & & & & & & & & & EI-SB & CPP-DB & CPP & NS-IA & El & $\begin{array}{c}\text { Short- } \\
\text { term } \\
\text { Disability }\end{array}$ & $\begin{array}{l}\text { Long- } \\
\text { term } \\
\text { Disability }\end{array}$ & $\begin{array}{l}\text { Cape Breton } \\
\text { Cancer Fund }\end{array}$ & \\
\hline PP1 & $51-64$ & Female & White & Breast & 1 & 5 & Employed & Drug plan & Y & Denied & Ineligible & Denied & $\mathrm{N}$ & N & N & Y & 32 \\
\hline PP2 & $<50$ & Female & White & Breast & 4 & 5 & Unemployed & None & Y & Ineligible & Ineligible & Ineligible & $\mathrm{N}$ & $\mathrm{N}$ & $\mathrm{N}$ & $\mathrm{Y}$ & $\begin{array}{c}0 \text { income after } \\
15 \text { wks. of El-SB } \\
\text { terminated }\end{array}$ \\
\hline PP3 & $51-64$ & Female & White & Breast & 1 & 1 & Employed & Drug plan & $Y$ & $\mathrm{~N}$ & N & Ineligible & $N$ & N & N & N & 28 \\
\hline PP4 & $51-64$ & Male & White & Prostate & 3 & 5 & Unemployed & None & $Y$ & Y & Ineligible & Ineligible & $\mathrm{Y}$ & N & N & $Y$ & 8 \\
\hline PP5 & $51-64$ & Male & White & Pancreas & 4 & 5 & Unemployed & None & Y & 700/month & Ineligible & Y & $\mathrm{N}$ & N & N & Y & 4 \\
\hline PP6 & $51-64$ & Female & White & Breast & 2 & 4 & Unemployed & $\begin{array}{l}\text { Drug plan; } \\
\text { LTD }\end{array}$ & $\mathrm{Y}$ & $\mathrm{N}$ & Ineligible & $\mathrm{N}$ & $\mathrm{N}$ & $\mathrm{N}$ & Y & $\mathrm{N}$ & 8 \\
\hline PP7 & $51-64$ & Male & White & Rectal & 3 & 5 & Unemployed & None & Y & Applied & Ineligible & Ineligible & $\mathrm{N}$ & N & $\mathrm{N}$ & Y & 2 \\
\hline PP8 & $51-64$ & Female & White & Breast & 1 & 4 & Unemployed & None & $\mathrm{Y}$ & $619 /$ month & Ineligible & $\mathrm{Y}$ & $\mathrm{N}$ & $\mathrm{N}$ & $\mathrm{N}$ & $\mathrm{Y}$ & 6 \\
\hline PP9 & $51-64$ & Female & White & Breast & 4 & 5 & Unemployed & None & Y & $800 /$ month & Ineligible & Ineligible & $N$ & N & N & N & 0 \\
\hline PP10 & $51-64$ & Male & White & Rectal & 4 & 5 & Unemployed & None & Y & $\begin{array}{c}\text { Ineligible } \\
\text { (at the time) }{ }^{b}\end{array}$ & $282 /$ month & Ineligible & $\mathrm{N}$ & $\mathrm{N}$ & $\mathrm{N}$ & Y & 0 \\
\hline PP11 & $51-64$ & Female & White & Breast & 1 & 4 & Employed PT & None & Y & 700/month & N & $\mathrm{N}$ & $\mathrm{N}$ & N & $\mathrm{N}$ & Y & 8 \\
\hline PP12 & $<50$ & Female & White & Breast & 4 & 5 & Employed PT & None & Y & 650/month & Ineligible & Ineligible & $\mathrm{N}$ & $\mathrm{N}$ & $\mathrm{N}$ & Y & 0 \\
\hline PP13 & $>65$ & Female & White & Breast & 3 & 5 & Unemployed & None & $Y$ & Ineligible & $800 /$ month & Ineligible & $\mathrm{N}$ & N & N & Y & 0 \\
\hline PP14 & $51-64$ & Male & White & Rectal & 3 & 5 & Unemployed & None & $Y$ & Applied & Ineligible & Ineligible & $\mathrm{N}$ & N & N & $Y$ & 0 \\
\hline PP15 & $51-64$ & Female & White & Breast & 1 & 5 & Unemployed & None & Y & $\begin{array}{c}\text { Ineligible } \\
\text { (at the time) }\end{array}$ & $320 /$ month & $\mathrm{N}$ & $\mathrm{N}$ & N & $\mathrm{N}$ & N & 24 \\
\hline PP16 & $51-64$ & Female & White & Breast & 1 & 5 & Unemployed & None & $Y$ & Applied & Ineligible & Ineligible & $\mathrm{N}$ & N & N & $\mathrm{N}$ & 0 \\
\hline PP17 & $51-64$ & Female & White & Lung & 4 & 5 & Unemployed & None & Y & 646/month & Ineligible & Ineligible & $N$ & N & $\mathrm{N}$ & Y & 3 \\
\hline PP18 & $51-64$ & Male & White & Lung & 4 & 5 & Unemployed & None & $\mathrm{Y}$ & $\begin{array}{c}\text { Ineligible } \\
\text { (at the time) }\end{array}$ & $\mathrm{Y}$ & Ineligible & $\mathrm{N}$ & N & $\mathrm{N}$ & Y & 0 \\
\hline PP19 & $51-64$ & Female & White & Breast & 3 & 4 & Employed & None & Y & N & Ineligible & Ineligible & $\mathrm{N}$ & N & N & $N$ & 0 \\
\hline PP20 & $>65$ & Female & White & Colon & 4 & 4 & Unemployed & None & $\mathrm{Y}$ & $\mathrm{Y}$ & Ineligible & $\mathrm{Y}$ & $\mathrm{N}$ & $\mathrm{N}$ & $\mathrm{N}$ & $\mathrm{N}$ & 0 \\
\hline
\end{tabular}

Abbreviations: LTD, Long-term disability; El, employment insurance; El-SB, employment insurance - sickness benefits; CPP, Canada Pension Plan; CPP-DB, Canada Pension Plan Disability Benefits.

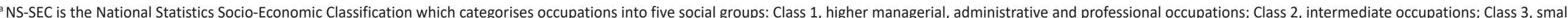
employers and own account workers; Class 4, lower supervisory and technical occupations; Class 5, semi-routine and routine occupations including manual labour.

${ }^{\mathrm{b}}$ As of January 1, 2019 persons in receipt of CPP regular benefits could apply for CPP-DB. 


\section{Economic exclusion}

Financial toxicity

distribution
-through

-through
labour

market

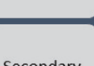

Secondary
distribution

- through

social safely

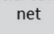

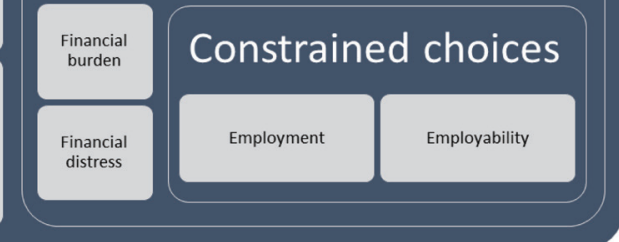

Figure 2. Themes and Subthemes of the Study.

aspects of their daily life became entangled with cancer. This included the cost of meeting regular monthly expenses as recounted by this participant:

"You still have all of your bills to pay. Life doesn't stop because you get cancer" (PP1).

For many participants this entanglement resulted in financial hardship and a struggle to make ends meet. Participants recounted how they prioritized expenses between medicines, food or gas:

"If it was medical, it came first. If it was food it came second. Gas came third. Anything after that we ain't doing it” (PP1).

Participants recounted gnawing away at any savings in order to make ends meet until there was nothing left as described by this participant:

"I didn't have a lot of savings. But you're continually chewing away at that. And it just comes to a point that the well dries up after a while" (PP10).

Participants who were unable to return to work found themselves in dire financial constraints. One participant described how she struggled to prove eligibility for welfare support whilst facing her own rapidly declining health:

"You spend so much time you are proving you are poor, getting photo copies of things... You have no idea how time consuming it is to be poor... But (even then) I was still below the poverty. Plus I was dealing with the fact that I was dying and my daughter was going to be an orphan. It was so terrible" (PP20).

The same participant suggested that a General Annual Income (which is not means-tested) would be a good way to provide income security to cancer patients in a way that would allow them to make ends meet without relying on a patchwork of supports:

"They have to get the cancer patients out of the welfare roles. They have to make accommodation for people who have worked all their lives and hit a hard patch and have nowhere to turn. The basic annual income, I'm telling you, if I had that, I would have never had to go to welfare or CPP because I would have been covered. I would have been able to pay my car insurance, house insurance, mortgage and buy some half decent food. You know instead, I had all this piece meal stuff... donations, friends ... it shouldn't be this way, it's wrong" (PP20).
Constrained Choices

We build on Max Weber's ${ }^{38}$ concept of life conduct and the limitation of one's choices to describe constrained choices as the variety of opportunities available to individuals based on access to material resources and social structure.

As a result of a significantly reduced income, some participants had no option but to return to the workforce. Participants who were employed at the time of the interview recounted this as a lack of choice as described by this participant:

"I could not financially stay off work. It was not an option for me to not earn whatever income I could" (PP19).

The need to return to work before being physically well enough to do so in order to afford basic expenses such as rent is recounted by this participant who was receiving income support which was not even sufficient to cover this monthly rent:

"(I got) \$700 a month. My rent is more than that. So I am forced. My options are, go back to work. I am a workaholic anyway, but am I going to go back sick? I got no choice; I got to go back to work" (PP5).

Several participants recounted health challenges that limited their ability to return to full time employment. For participants receiving chemotherapy this implied avoiding a crowded workplace where they would have to compromise their health by exposing themselves to a higher infection rate as described by this participant:

"And when your immune system is compromised, like to throw me back into my workplace, there is, somebody's sick all the time like that would be compromising me until I'm healthy enough to return there" (PP6).

Other participants were not able to return to their prior employment because of the physical impact of cancer on their health. One participant recounted how she felt weak and tired most of the time, and despite her desire to return to work she was not physically able to do so:

"Right now, I'm very weak. My legs are tired all the time. They are just like Jello. I'm walking with a cane. So it's not...for the amount of walking that I do at the office, um, it's kind of hard to walk with a cane and carry a bunch of papers or whatever. And plus the tiredness, I'm tired a lot so I wouldn't be able to just go and say 'I'm going to take a nap now' I'd have to work around... I'd be draining myself too much if I went back to work right at this moment, I'd love too, but, it just can't be done" (PP17).

Several participants felt that their ability to perform well at a job had been compromised by the impact of cancer on their health and wellbeing as described by this participant:

"Most jobs out there, people are looking for good, solid employees they can depend on. And, now due to my sickness, I don't feel I'm one of them" (PP10).

Participants that were willing and able to work described themselves as trapped between a health condition requiring intensive monitoring and support on one hand, and a lack of flexible job opportunities that would be suitable to their needs on the other hand:

"You have a double-whammy. You are trying to recover from your illness and you don't have a job... It's like (the 
lack of) job opportunities too, they are coinciding at the same time. Who is going to hire you if you've got doctor's appointments that you're going to back and forth. So it seems like you're contending with kind of a struggle on both ends" (PP3).

Several participants shared a desire to return to work part time. As recounted by this participant, returning to work part time would have been the ideal case scenario, facilitating her to gradually reintegrate into the workforce:

"In an ideal world I could have returned to work part time, but I didn't have that option because I didn't have a job to return to. So, reintegration into the workforce would have been better" (PP19).

\section{Discussion}

In Canada, a patch work of short and long-term income supports are available through either public or private health plans to assist individuals when they are unable to return to work because of illness or disability. Private income support plans are benefits provided through employment. However, approximately half of all employed Canadians do not have adequate disability coverage through their workplace ${ }^{25}$ and this is directly linked to the increasing precarity of jobs which provide minimum wage and offer little or no workplace benefits. ${ }^{25,39}$ Individuals who do not have workplace benefits must resort to social insurance programs such as EI-SB for income support when they need to take time off work due to an illness.

While the goal of EI-SB is to provide income continuity in the face of an illness, our study participants described how the short duration of EI-SB (15 weeks) and strict eligibility criteria for other income support programs such as CPPDB (disease must be both severe and prolonged rendering individual incapable of working) left participants scrambling to make ends meet and with feelings of anger and frustration as they juggled their health and financial needs. Current income support programs are ill-suited to the complex needs of cancer patients for whom treatment can take between 16 to 24 weeks and include a combination of surgery with or without chemotherapy or radiotherapy. This duration does not include time needed for additional treatment (further surgery/radiation), side-effects of therapy, or the physical and psychological toll of cancer on the patient. Further to this, income replaced through EI-SB and CPP-DB is at levels below the poverty line. Participants in our study endured financial hardship due to their healthcare needs and concurrently struggled with finding suitable employment. Choices were most constrained for participants who were women and individuals between the ages of 51-64 years.

The vicious cycle of financial burden and financial distress did not occur in a vacuum. Participants described how they were structurally excluded from participating in full-time, well-paid jobs with benefits. Indeed, the majority of our study participants were working contractual jobs with no benefits. Subsequently, when diagnosed with cancer, participants were forced to leave their jobs and had no financial recourse. The structure of the labour market is responsible for the primary distribution of material capital through the provision of adequate income and financial security. ${ }^{40}$ In Canada, contingent labour, ie, temporary workers with no benefits ${ }^{41}$ make up approximately $30 \%$ of the labour market. As full-time, well-paying jobs continue to decline in Canada ${ }^{42}$ it is crucial to implement public policies which strengthen working conditions for employees. This is particularly important given the parallel increase in cancer incidence across the country. ${ }^{1}$ Once cancer patients are physically and psychologically ready to return to work, it will be important to support them through multidisciplinary programs which facilitate retraining and reintegration into the labour market. Ideally, these programs should be an integral component of cancer survivorship care. ${ }^{43}$

The social welfare system is responsible for the secondary redistribution of material capital. Recent cuts in social services spending leading to reduced social assistance, and a meanstested distribution policy imply that many individuals are left scrambling to prove eligibility. All of our study participants had received EI-SB. However, only a few were eligible for CPPDB. Others accessed other forms of income support such as $\mathrm{CPP}$ or Income Assistance through welfare. The Cape Breton Cancer Fund was an additional source of income support for participants who could not qualify for any of the publiclyfunded income programs. Most participants experienced multiple weeks where they did not have any source of income support. The patchwork of income support programs resulted in stress, financial hardship, and loss of dignity. All of these are associated with deepening financial toxicity ${ }^{9}$ and poorer cancer-related health outcomes. ${ }^{7,16}$ Twelve of our participants had advanced stage cancer (stage 3 or 4 ). The average income support for these participants was reported at $\$ 500$ a month, an amount well below the low income cut-offs in Canada. ${ }^{44}$ These participants recounted a continuous struggle with bills, and payment for food and gas.

Most of our study participants were between the ages of 51-64 years. For this demographic age group, described as preseniors, ${ }^{45}$ financial hardship was intensified as participants found themselves caught between a loss of income due to illness, a lack of job opportunities suitable to their needs, and an inability to tap into pension and social benefits available to those over the age of 65 years. Participants described how they depleted any or all of their savings, struggled to prove their eligibility for other income support programs, and contested between diminishing health and the ability to work. Given that the incidence of cancer rapidly begins to increase after the age of 50 years, ${ }^{2}$ it is important that public policy programs take into consideration the complex challenges of cancer risk that intersect with a propensity towards economic hardship for preseniors. ${ }^{45}$

Our study illuminates the urgent need to revisit the structure of income assistance programs for cancer patients. Among industrialized nations, Canada's EI-SB program provides one of the shortest duration of benefits. ${ }^{46}$ Ninety countries provide benefits of a longer duration and 127 countries provide higher levels of wage replacement. ${ }^{47}$ For those unable to return to work, the CPP-DB provides less than the low income cut-off ${ }^{44}$ and is considered among the least generous of public initiatives. ${ }^{39}$ The duration and amount of benefits 
do not currently correspond with the complex treatment and prognosis of cancer. Alternate eligibility criteria for regular EI and/or CPP for patients with advanced stage cancer will ensure that they are able to avail benefits which they have accrued during their end-of-life care. As suggested by one participant, a Guaranteed Annual Income ${ }^{48}$ would alleviate much of the stress associated with proving eligibility, and would enable cancer patients to meet their monthly expenses while focusing on recovery or palliation in a dignified way. Ultimately, emphasis needs to be placed on the upstream determinants of cancer risk, treatment and survival ${ }^{24}$ in order to improve the quality and distribution of the social determinants of health as they intersect across the cancer care continuum. $^{23}$

Our study participants were all white, mostly between the ages of 51-64 years, majority female and part of the contingent labour workforce. This can reflect the way in which we recruited participants from social services at a cancer care centre with a demographically homogenous patient population. However, it can also illuminate the disproportionate representation of individuals who are preseniors in precarious working conditions that need income support in order to make ends meet when they are diagnosed with cancer. This warrants further exploration. The over-representation of females in our study sample mirrors what is currently known in the literature about gender-based inequities. Women are more likely to be precariously employed with little to no access to benefits ${ }^{49}$ and have fewer opportunities to return to work after cancer. ${ }^{50}$

The increasing incidence of cancer with high levels of survivorship on one hand, and the greater economic exclusion of individuals through the labour market and social welfare programs on the other hand create a profound gap in income support available to cancer patients when they fall ill and are unable to return to work. Closing these gaps will require a mix of working conditions that provide financial security with workplace benefits along with a redesign of public income support programs to respond specifically to the chronicity and complexity of the needs of cancer patients. As a qualitative study, we do not expect our work to be generalizable, however we believe that by describing our study setting and participant population, our findings will be transferable to other jurisdictions seeking to address income support gaps for cancer patients.

\section{Conclusion}

Cancer patients employed in precarious working conditions can find themselves unemployed and without access to any workplace benefits upon falling ill. As a result, cancer patients turn to social welfare programs such as EI-SB for income support during their illness. Financial compensation awarded through the EI-SB is insufficient in duration. The CPP-DB has strict eligibility criteria which cancer patients can struggle to prove. The income offered through both programs is bare minimum and cancer patients, including those with terminal cancer can find themselves struggling to make ends meet as benefits offered are well below the poverty line. An increasing incidence of cancer, a rise in precarious working conditions, and cuts to social services spending result in a porous system which fails to protect and support cancer patients during a period of intense financial hardship. A redesign of income support programs tailored to the needs of cancer patients is urgently needed. In addition, public policies which strengthen working conditions, provide adequate income support to Canadians when they are ill, and facilitate a reintegration into work when possible will be important in responding to the complexity and chronicity of cancer.

\section{Acknowledgements}

The authors would like to thank the study participants who have contributed to our shared understanding of the lived experiences of income insecurity as a cancer patient.

\section{Ethical issues}

Research ethics board approval was obtained from Nova Scotia Health Authority Research Ethics Board.

\section{Competing interests}

AS reports a Postdoctoral Fellowship Award in Patient-Oriented Research from the Canadian Institutes for Health Research. JD, JLK, and TM have nothing to disclose.

\section{Authors' contributions}

Study was conceptualised by TM. Material preparation was done by TM and reviewed by JD. Data was collected by TM and JD. Coding was done by AS, JLK and TM. AS, JLK, JD, and TM analysed the data. The first draft of the manuscript was written by AS and all authors commented on previous versions of the manuscript. All authors read and approved the final manuscript.

\section{Authors' affiliations}

'Women's College Research Institute, Women's College Hospital, Toronto, ON, Canada. ${ }^{2}$ Nova Scotia Health Authority, Cape Breton Regional Hospital, Sydney, NS, Canada. ${ }^{3}$ School of Professional Studies, Cape Breton University, Sydney, NS, Canada. ${ }^{4}$ Cape Breton Cancer Centre, Sydney, NS, Canada.

\section{References}

1. Brenner DR, Weir HK, Demers AA, et al. Projected estimates of cancer in Canada in 2020. CMAJ. 2020;192(9):E199-e205. doi:10.1503/ cmaj.191292

2. Canadian Cancer Society's Advisory Committee on Cancer. Canadian Cancer Statistics 2019. https://www.cancer.ca:443/en/cancer-information/ cancer-101/canadian-cancer-statistics-publication/?region=bc. Accessed September 10, 2019.

3. Canadian Cancer Society's Advisory Committee on Cancer, Statistics. Canadian Cancer Statistics 2017. http://www.cancer.ca/ /media/cancer. ca/CW/cancer\%20information/cancer\%20101/Canadian\%20cancer\%20 statistics/Canadian-Cancer-Statistics-2017-EN.pdf?la=en. Accessed January 19, 2018.

4. Chi M. The hidden cost of cancer: helping clients cope with financial toxicity. Clin Soc Work J. 2019;47(3):249-257. doi:10.1007/s10615-0170640-7

5. Hanratty B, Holland P, Jacoby A, Whitehead M. Financial stress and strain associated with terminal cancer--a review of the evidence. Palliat Med. 2007;21(7):595-607. doi:10.1177/0269216307082476

6. Longo CJ, Bereza BG. A comparative analysis of monthly out-of-pocket costs for patients with breast cancer as compared with other common cancers in Ontario, Canada. Curr Oncol. 2011;18(1):e1-8. doi:10.3747/ co.v18i1.681

7. Fenn KM, Evans SB, McCorkle R, et al. Impact of financial burden of cancer on survivors' quality of life. J Oncol Pract. 2014;10(5):332-338. doi:10.1200/jop.2013.001322

8. Schröder SL, Schumann N, Fink A, Richter M. Coping mechanisms for financial toxicity: a qualitative study of cancer patients' experiences in Germany. Support Care Cancer. 2020;28(3):1131-1139. doi:10.1007/ s00520-019-04915-w

9. Carrera PM, Kantarjian HM, Blinder VS. The financial burden and distress of patients with cancer: understanding and stepping-up action on the financial toxicity of cancer treatment. CA Cancer J Clin. 2018;68(2):153- 
165. doi:10.3322/caac.21443

10. Blum-Barnett E, Madrid S, Burnett-Hartman A, et al. Financial burden and quality of life among early-onset colorectal cancer survivors: a qualitative analysis. Health Expect. 2019;22(5):1050-1057. doi:10.1111/hex.12919

11. Semin JN, Palm D, Smith LM, Ruttle S. Understanding breast cancer survivors' financial burden and distress after financial assistance. Support Care Cancer. 2020;28(9):4241-4248. doi:10.1007/s00520-019-05271-5

12. Reeder-Hayes KE, Wheeler SB, Mayer DK. Health disparities across the breast cancer continuum. Semin Oncol Nurs. 2015;31(2):170-177. doi:10.1016/j.soncn.2015.02.005

13. Zajacova A, Dowd JB, Schoeni RF, Wallace RB. Employment and income losses among cancer survivors: estimates from a national longitudinal survey of American families. Cancer. 2015;121(24):4425-4432. doi:10.1002/cncr.29510

14. Koczwara B. Unemployment after cancer-a hidden driver of financial toxicity. Cancer Forum. 2017;4(2):36-41. doi:10.3316/informit.112480005521216

15. Head B, Harris L, Kayser K, Martin A, Smith L. As if the disease was not enough: coping with the financial consequences of cancer. Support Care Cancer. 2018;26(3):975-987. doi:10.1007/s00520-017-3918-y

16. Sharp L, Carsin AE, Timmons A. Associations between cancer-related financial stress and strain and psychological well-being among individuals living with cancer. Psychooncology. 2013;22(4):745-755. doi:10.1002/ pon.3055

17. Torp S, Nielsen RA, Gudbergsson SB, Fosså SD, Dahl AA. Sick leave patterns among 5-year cancer survivors: a registry-based retrospective cohort study. J Cancer Surviv. 2012;6(3):315-323. doi:10.1007/s11764012-0228-8

18. Mehnert A. Employment and work-related issues in cancer survivors. Crit Rev Oncol Hematol. 2011;77(2):109-130. doi:10.1016/j. critrevonc. 2010.01.004

19. Pryce J, Munir F, Haslam C. Cancer survivorship and work: symptoms, supervisor response, co-worker disclosure and work adjustment. J Occup Rehabil. 2007;17(1):83-92. doi:10.1007/s10926-006-9040-5

20. Sinding C. Using institutional ethnography to understand the production of health care disparities. Qual Health Res. 2010;20(12):1656-1663. doi:10.1177/1049732310377452

21. Groome PA, Schulze KM, Keller S, Mackillop WJ. Demographic differences between cancer survivors and those who die quickly of their disease. Clin Oncol (R Coll Radiol). 2008;20(8):647-656. doi:10.1016/j. clon.2008.05.006

22. Ward E, Jemal A, Cokkinides $\mathrm{V}$, et al. Cancer disparities by race/ ethnicity and socioeconomic status. CA Cancer J Clin. 2004;54(2):78-93. doi:10.3322/canjclin.54.2.78

23. Sayani A. Socially based inequities in breast cancer care: intersections of the social determinants of health and the cancer care continuum. Critical Studies: An International and Interdisciplinary Journal. 2017;13(1):24-36.

24. Sayani A. Social class and health inequalities. In: Raphael D, Bryant T, Rioux MH, eds. Staying Alive: Critical Perspectives on Health, Illness and Healthcare. 3rd ed. Canadian Scholars' Press Inc; 2019.

25. Meredith T, Chia C. Leaving Some Behind: What Happens When Workers Get Sick. Institute for Research on Public Policy: Technical Report; 2015. https://irpp.org/wp-content/uploads/2015/09/report-2015-09-03.pdf. Accessed September 20, 2020.

26. Government of Canada. Employment insurance (EI) sickness benefits. aem. https://www.canada.ca/en/services/benefits/ei/ei-sickness.html. Published November 30, 2015. Accessed September 20, 2020.

27. Braun V, Clarke V. Using thematic analysis in psychology. Qual Res Psychol. 2006;3(2):77-101. doi:10.1191/1478088706qp063oa

28. McGibbon E, McPherson C. Applying Intersectionality \& Complexity Theory to Address the Social Determinants of Women's Health. https:// tspace.library.utoronto.ca/handle/1807/27217. Accessed October 5, 2015. Published May 2011.

29. Sayani A. Inequities in genetic testing for hereditary breast cancer: implications for public health practice. J Community Genet. 2019;10(1):3539. doi:10.1007/s12687-018-0370-8

30. Sayani A, Vahabi M, O'Brien MA, et al. Perspectives of family physicians towards access to lung cancer screening for individuals living with low income - a qualitative study. BMC Fam Pract. 2021;22(1):10. doi:10.1186/ s12875-020-01354-z

31. Sayani A. Health equity in national cancer control plans: an analysis of the Ontario Cancer Plan. Int J Health Policy Manag. 2019;8(9):550-556. doi:10.15171/ijhpm.2019.40

32. Taplin SH, Anhang Price R, Edwards HM, et al. Introduction: understanding and influencing multilevel factors across the cancer care continuum. J Nat Cancer Inst Monogr. 2012;2012(44):2-10. doi:10.1093/jncimonographs/ Igs008

33. Saunders B, Sim J, Kingstone T, et al. Saturation in qualitative research: exploring its conceptualization and operationalization. Qual Quant. 2018;52(4):1893-1907. doi:10.1007/s11135-017-0574-8

34. Braun V, Clarke V. What can "thematic analysis" offer health and wellbeing researchers? Int J Qual Stud Health Well-being. 2014;9:26152. doi:10.3402/qhw.v9.26152

35. Lincoln YS, Guba EG. Naturalistic Inquiry. 1st ed. SAGE Publications 1985.

36. Lightman ES, Lightman N. Social Policy in Canada. Oxford University Press; 2017.

37. Lightman N, Good Gingrich L. Measuring economic exclusion for racialized minorities, immigrants and women in Canada: results from 2000 and 2010. J Poverty. 2018;22(5):398-420. doi:10.1080/10875549. 2018.1460736

38. Roth G, Wittich C, eds. Weber M. Economy and Society. University of California Press; 1978.

39. Prince MJ. Canadians Need a Medium-Term Sickness/Disability Income Benefit. Ottawa, ON: Caledon Institute of Social Policy; 2008.

40. Raphael D. Social determinants of health: present status, unanswered questions, and future directions. Int J Health Serv. 2006;36(4):651-677. doi:10.2190/3mw4-1ek3-dgrq-2crf

41. Mancini J. Historical roots - why in a time of unprecedented wealth and health do we have homelessness and ill health? In: Arya AN, Piggott T, eds. Under-Served: Health Determinants of Indigenous, Inner-City, and Migrant Populations in Canada. 1st ed. Canadian Scholars' Press Inc; 2018:121-129.

42. Gaetz S, Dej E, Richter T. Homelessness Canada in the State of 2016 http://www.deslibris.ca/ID/10065873. Accessed December 29, 2019.

43. Pearce A, Tomalin B, Kaambwa B, et al. Financial toxicity is more than costs of care: the relationship between employment and financial toxicity in long-term cancer survivors. J Cancer Surviv. 2019;13(1):10-20 doi:10.1007/s11764-018-0723-7

44. Government of Canada SC. Low income cut-offs (LICOs) before and after tax by community size and family size, in current dollars. https://www150. statcan.gc.ca/t1/tbl1/en/tv.action?pid=1110024101. Published February 26, 2019. Accessed September 21, 2020.

45. Walsh CA, Hewson J, Paul K, Gulbrandsen C, Dooley D. Falling through the cracks: exploring the subsidized housing needs of low-income preseniors from the perspectives of housing providers. Sage Open. 2015;5(3):2158244015607353. doi:10.1177/2158244015607353

46. Nelson C. The Financial Hardship of Cancer in Canada: A Literature Review. Canadian Cancer Society Report; 2010. https://www.cancer. ca/ /media/cancer.ca/MB/get\%20involved/take\%20action/financial\%20 hardship\%20of\%20cancer\%20in\%20canada/aliteraturereview-MB. pdf?la=en. Accessed February 18, 2021.

47. Heymann SJ, Gerecke M, Chaussard M. Paid health and family leave: the Canadian experience in the global context. Can J Public Health. 2010;101 Suppl 1:S9-15. doi:10.1007/bf03403840

48. McIntyre L, Dutton DJ, Kwok C, Emery JH. Reduction of food insecurity among low-income Canadian seniors as a likely impact of a guaranteed annual income. Can Public Policy. 2016;42(3):274-286. doi:10.3138/ cpp.2015-069

49. Vissandjée B, Weinfeld M, Dupéré S, Abdool S. Sex, gender, ethnicity, and access to health care services: Research and policy challenges for immigrant women in Canada. J Int Migr Integr. 2001;2(1):55-75. doi:10.1007/s12134-001-1019-7

50. Paalman $\mathrm{CH}$, van Leeuwen FE, Aaronson NK, et al. Employment and social benefits up to 10 years after breast cancer diagnosis: a populationbased study. Br J Cancer. 2016;114(1):81-87. doi:10.1038/bjc.2015.431 